\title{
Polyunsaturated fatty acids in fish tissues more closely resemble algal than terrestrial diet sources
}

\author{
Nadine Ebm $(\mathbb{D} \cdot$ Fen Guo $(\mathbb{D} \cdot$ Michael T. Brett $(\mathbb{D} \cdot$ Stuart E. Bunn $(\mathbb{D} \cdot$ \\ Martin J. Kainz $\mathbb{D}$
}

Received: 15 July 2020/Revised: 13 October 2020/Accepted: 15 October 2020/Published online: 16 November 2020

(C) The Author(s) 2020

\begin{abstract}
The River Continuum Concept implies that consumers in headwater streams have greater dietary access to terrestrial basal resources, but recent studies have highlighted the dietary importance of high-quality algae. Algae provide consumers with physiologically important omega-3 (n-3) polyunsaturated fatty acids (PUFA), particularly eicosapentaenoic acid (EPA). However, terrestrial plants and most benthic stream algae lack the long-chain (LC) n-3 PUFA docosahexaenoic acid (DHA, 22:6n-3),
\end{abstract}

Handling editor: Michael Power

Electronic supplementary material The online version of this article (https://doi.org/10.1007/s10750-020-04445-1) contains supplementary material, which is available to authorized users.

N. Ebm · M. J. Kainz ( $\square)$

WasserCluster Lunz - Inter-university Center for Aquatic

Ecosystem Studies, 3293 Lunz Am See, Austria

e-mail: martin.kainz@donau-uni.ac.at

N. Ebm

e-mail: nadine.ebm@outlook.com

N. Ebm

Functional and Evolutionary Ecology, Faculty of Life

Sciences, University of Vienna, 1090 Vienna, Austria

F. Guo

Simon F.S. Li Marine Science Laboratory, School of Life

Sciences, The Chinese University of Hong Kong,

Hong Kong, China

e-mail: fenguo@cuhk.edu.hk which is essential for neural development in fish and other vertebrates. We sampled subalpine streams to investigate how the PUFA composition of neural (brain and eyes), muscle, and liver tissues of freshwater fish is related to their potential diets (macroinvertebrates, epilithon, fresh and conditioned terrestrial leaves). The PUFA composition of consumers was more similar to epilithon than to terrestrial leaves. Storage lipids of eyes most closely resembled dietary PUFA (aquatic invertebrates and algae). However, DHA and arachidonic acid (ARA, 20:4n-6) were not directly available in the diet but abundant in organs. This implies that algal PUFA were selectively retained or were produced internally via enzymatic PUFA conversion by aquatic consumers. This field study demonstrates the nutritional importance of algal

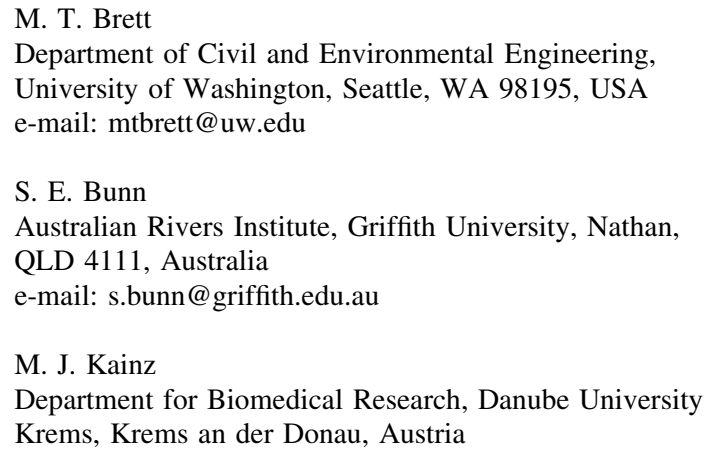

S. E. Bunn

Australian Rivers Institute, Griffith University, Nathan,

QLD 4111, Australia

e-mail: s.bunn@griffith.edu.au

M. J. Kainz

Department for Biomedical Research, Danube University

Krems, Krems an der Donau, Austria 
PUFA for neural organs in aquatic consumers of headwater regions.

Keywords Stream food webs - Food quality · Headwaters · Fish brain · Fish eyes · Docosahexaenoic acid

\section{Introduction}

At the base of aquatic food webs, primary producers, e.g., microalgae, provide consumers with dietary nutrients, including essential polyunsaturated fatty acids (PUFA), that are crucial constituents of cell membranes (e.g., phospholipids). A steady supply of dietary PUFA to aquatic consumers, particularly omega-3 (n-3) long-chain (LC) PUFA, such as eicosapentaenoic acid (EPA; 20:5n-3) and docosahexaenoic acid (DHA; 22:6n-3), is critical as these fatty acids (FA) support somatic growth and reproduction (Müller-Navarra et al., 2000; Brett et al., 2009). However, most aquatic consumers have limited abilities to synthesize EPA and DHA and thus have to take up these biomolecules directly from their diets (Brett \& Müller-Navarra, 1997; Arts et al., 2009; TorresRuiz et al., 2010). Vascular plants synthesize the shortchain PUFA: alpha-linolenic acid (ALA; 18:3n-3) and the n-6 PUFA linoleic acid (LA, 18:2n-6), but generally lack EPA and DHA (Brett et al., 2009; but see Napier, 2006). Although epilithic algae (especially diatoms) in freshwater ecosystems are comparatively rich in EPA, they are low in DHA (Brett et al., 2009; Hixson et al., 2015; Guo et al., 2018). However, DHA is essential for all vertebrates including freshwater fishes (Ahlgren et al., 1994; Guo et al., 2017) where it is associated with high membrane fluidity (e.g., signal transduction, neurotransmission or hormone regulation, Farkas et al., 2000), anti-inflammatory andoxidative effects (e.g., neuroprotection, Bazan, 2005), proper neural development (cognitive performance, Lund et al., 2014), and sensory functioning (visual acuity, Bell et al., 1995).

In contrast to marine fish (Agaba et al., 2005; Tocher et al., 2006; Mohd-Yusof et al., 2010), previous studies have reported that enzymatic conversions to LC-PUFA are functional in some freshwater fish (e.g., Oncorhynchus mykiss (Walbaum, 1792), Salvelinus alpinus (Linnaeus, 1758), Buzzi et al.,
1996; Tocher et al., 2001; Murray et al., 2014). These fish are able to transform dietary ALA via stearidonic acid (SDA) and EPA to DHA, but direct incorporation of dietary DHA is preferred by fish as it reduces the more energy-demanding endogenous production pathway. However, in contrast to such experimental studies, little is known about the PUFA pathways to and within fish in natural ecosystems deprived in DHA (Gladyshev et al., 2018), and especially how fish in streams acquire their PUFA and subsequently allocate these FA to different organs, including neural organs (Guo et al., 2017).

Neural organs, e.g., brain and eyes, are rich in DHA (Mourente \& Tocher, 1998; Farkas et al., 2000; Stoknes et al., 2004), which is key for proper functioning of these organs and eventually optimal fish physiological performance. Common stream fish in alpine headwaters (e.g., salmonids and European bullhead) are visual predators that prey mostly on moving or drifting invertebrates oftentimes at night (Elliott, 1973; Mills \& Mann, 1983). A reduced visual performance (Bell et al., 1995) or learning ability (Lund et al., 2014) of fish due to LC-PUFA-poor diets can reduce feeding success, predator avoidance (e.g., escape latency, swimming speed) and other behavioral traits, e.g., schooling behavior (Ishizaki et al., 2001). Despite the fact that neural organs have the highest lipid contents and are the most energy-demanding tissues in animals, our current knowledge about energy flows in aquatic food webs is primarily derived from studies on fish muscle and liver tissues (Volk \& Kiffney, 2012; Kainz et al., 2017; Sushchik et al., 2018). Previous research indicated that FA in neutral lipids (NL) of fish muscles, such as triacylglycerols (TAG), reflect those from the diet, while FA in the polar lipids (PL) of fish muscles are driven by taxonomy (Iverson 2009; Sushchik et al., 2020). Total lipids and TAG contents vary among fish organs (Tocher \& Harvie, 1988; Budge et al., 2006; Hong et al., 2014) and thus different organs may vary in correspondence to dietary FA.

Most vertebrate and fish brains consist mainly of PL (Soengas \& Aldegunde, 2002), which are rich in DHA (Tocher \& Harvie, 1988; Iverson, 2009), making them indispensable for cell functionality and relatively stable to dietary lipid intake. In contrast, fish eyes are rich in TAG (Mourente et al., 1991; Geurden et al., 1998; Stoknes et al., 2004) and thus eye lipids may reflect dietary PUFA sources better than brain lipids 
(Brodtkorb et al., 1997). Bell et al. (1995) demonstrated that DHA-poor diets resulted in DHA-deficit retina membranes with impaired vision under natural light intensities. It is thus important to understand how lipid classes in neural organs are affected by dietary FA. However, this has not been tested yet for stream fish which receive very little DHA directly from organisms at the base of the food chain.

Motivated by the ambiguities outlined above, we designed a field study to investigate the PUFA distribution in freshwater fish and their potential diet sources in subalpine streams. We compared the PUFA composition of various fish organs, i.e., muscle, liver, brain, and eyes, with PUFA of potential diet sources (terrestrial plants, benthic algae and macroinvertebrates), and also explored the FA distribution of salmonid brain and eyes in an effort to discern how different lipid classes (NL versus PL) of these neural organs are affected by dietary PUFA sources. We tested the hypotheses that, (1) the PUFA composition of stream consumers (macroinvertebrates and fish) is generally more similar to epilithon than to the leaves of terrestrial vascular plants, and, (2) fish eyes have a greater similarity with dietary PUFA than fish brains due to differences in lipid class composition.

\section{Methods}

\section{Study streams}

We sampled 17 sites in 9 oligotrophic streams (1st-5th order, total length $\sim 42 \mathrm{~km}$ ) within the headwater region ('Weiße Ois') of the subalpine River Ybbs catchment, Austria (Online resource 1). The study catchment (550-1000 m.a.s.1.) has a nivo-pluvial flow regime that drains $254 \mathrm{~km}^{2}$ and is characterized by glaciokarst and dolomite $(82 \%)$, with forests $(82 \%)$ and alpine meadows $(11 \%)$ the predominant land cover forms (Besemer et al., 2013). The river substratum is dominated by gravel and cobble with intense bed-load transport during peak flows. The typical fish species in these study streams are Brown trout (Salmo trutta fario Linnaeus, 1758), European bullhead (Cottus gobio Linnaeus, 1758), European grayling (Thymallus thymallus Linnaeus, 1758) and Rainbow trout (Oncorhynchus mykiss). Stocking of Brown and Rainbow trout is reported but only at the downstream study sites (YKL, YLG, and YGL). Chemical parameter $\left(\mathrm{N}-\mathrm{NO}_{3}, \mathrm{~N}-\mathrm{NH}_{4}, \mathrm{P}-\mathrm{PO}_{4}\right)$, soluble reactive phosphorus (SRP), and dissolved organic matter (DOM) concentrations in these study streams were reported in a previous study (Guo et al., 2018).

Sample collection

Potential dietary resources for fishes, including epilithon, conditioned terrestrial leaves, and aquatic invertebrates were collected in October 2016. Conditioned leaves (submerged, senescent, and brownish leaves of various vascular plant species) were collected from streams). Epilithon from each of the sampling sites was transferred into sample containers from small cobbles using soft brushes and invertebrates were picked from rocks. The taxonomic composition of epilithon and periphyton (biofilm on submerged leaves) was not examined because we were primarily interested in their dietary and biochemical composition (Guo et al., 2018). Fresh leaves were picked directly from riparian vegetation in summer (July 2016). These samples included angiosperms (Acer, Alnus, Corylus avellana L., Fagus sylvatica L., Hedera helix L., Phragmites, Salix and gymnosperms (Picea and Pinus) and each plant species was analyzed separately.

Macroinvertebrates were identified to the genus level using a stereomicroscope and pooled by species for lipid analyses. Macroinvertebrate samples included Ephemeroptera (Baetis, Ecdyonurus, Rhithrogena), Plecoptera (Leuctra, Nemoura, Perla, Perlodes, Isoperla), Trichoptera (Allogamus, Odontoceridae, Plectronemia, Potamophylax, Rhyacophila, Hydropsyche), Platyhelminthes and the amphipod Gammarus.

Fish capture and collection for this research was permitted by the local fisheries authorities for these study streams. Individuals of three fish (O. mykiss, $S$. trutta, and $C$. gobio) were collected by electrofishing in November 2016, anesthetized and subsequently killed in accordance with the Federal Act on the Protection of Animals, Austria (http://www.ris.bka. gv.at). Fish total body length (mm) and weight (g) were recorded (Online Resource 2). No fish were found at the Schelchen ( $\mathrm{SCH}$ ) sampling site. Invertebrate samples were kept on ice in a portable cooling box and stored at cryogenic temperature $\left(-80^{\circ} \mathrm{C}\right)$ in the lab. Fishes were dissected and samples of the dorsal muscle and the entire liver of each specimen 
were collected. Dermis and subcutaneous tissue of each muscle sample were removed and excluded from further biochemical analyses. Entire brains and eyeballs together, with the optic nerve, were removed from each fish. In some cases, in particular for European bullhead, some eye or brain samples had to be pooled prior to lipid extraction (1-5 individuals matched for similar size from each sampling site) to obtain sufficient biomass for lipid analysis. All samples were stored on ice during dissection, placed into Eppendorf tubes (brain and eyes) or scintillation vials (muscle and liver) and stored at cryogenic temperature $\left(-80^{\circ} \mathrm{C}\right)$ until lyophilization (Virtis Genesis ${ }^{\mathrm{TM}}$ freeze dryer).

\section{Lipid analyses}

\section{Total lipid extraction}

Lipids and their FA were analyzed as described by Guo et al. (2015). Briefly, total lipids from freezedried (i.e., all lipids and FA were reported as dry weight; DW) and homogenized samples (fresh and conditioned terrestrial leaves: $\sim 50 \mathrm{mg}$, epilithon: $\sim 10 \mathrm{mg}$, invertebrates: $\sim 5$ to $7 \mathrm{mg}$, brain and eyes: $\sim 5 \mathrm{mg}$, liver: $\sim 10$ to $15 \mathrm{mg}$, muscle: $\sim 15$ to $20 \mathrm{mg}$ ) were dissolved in ice-cold chloroform $(2 \mathrm{~mL})$ and stored under $\mathrm{N}_{2}$ atmosphere over night at $-80^{\circ} \mathrm{C}$ to improve lipid extraction efficiency. Samples were then further extracted in chloroform-methanol (2:1) and $\mathrm{NaCl}(0.8 \mathrm{~mL}$; salt wash), vortexed and sonicated, and subsequently analyzed gravimetrically in pre-weighed tin capsules (total lipid content determination).

\section{Lipid class separation}

Only salmonids (S. trutta and O. mykiss) were used for the analysis of FA in lipid classes in neural organs because of limited material for lipid class separation for European bullhead brain and eye samples. Lipid extracts of selected salmonid brain and eye samples were separated into lipid classes by thin-layer chromatography (TLC). Mass ratios of lipid extracts were adjusted after gravimetry with chloroform to obtain similar lipid amounts (150-200 $\mu \mathrm{g}$ ) in the volume (50 $\mu \mathrm{L}$ ) applied to the TLC plates for salmonid brain and eye samples only. Polar (membrane lipids, PL) and neutral lipids (storage lipids, NL) were separated by one-dimensional TLC on $10 \times 10 \mathrm{~cm}$ silica gel plates (Merck TLC silica gel 60) using a hexane:diethylether:methanol:formic acid (90:20:3:2, v/v/v/v) solvent solution. After development, plates were sprayed with $0.05 \%$ (wt/vol) 8-anilino-4-naphthalenesulfonic acid in methanol and viewed under UV light to detect lipid fractions (Online resource 3). An internal standard $(5 \mu \mathrm{L}$; non-adecanoic acid in chloroform; $4 \mathrm{mg} \mathrm{mL}$ ) was added to each lipid fraction before individual lipid fractions were scraped from the TLC plates and transferred into separate solventrinsed vials.

\section{Fatty acid methylation and analysis}

Fatty acids from total lipid extracts and after lipid class separation were derivatized to fatty acid methyl esters (FAME) in a $\mathrm{H}_{2} \mathrm{SO}_{4}$ methanol solution for $16 \mathrm{~h}$ at $50^{\circ} \mathrm{C}$. All FAME were stored at $-80^{\circ} \mathrm{C}$ until being separated using gas chromatography $\left(\mathrm{THERMO}^{\mathrm{TM}}\right.$ Trace GC) and detected using flame ionization detection (FID). FAME were separated by a Supelco ${ }^{\text {TM }}$ SP2560 column $(100 \mathrm{~m}, 25 \mathrm{~mm}$ i.d., $0.2 \mu \mathrm{m}$ film thickness), identified by comparison to the retention times of known standards (37-component FAME Mix, Supelco 47885-U; Bacterial Acid Methyl Ester Mix, Supelco 47080-U). The FAME concentrations were quantified using calibration curves based on known standard concentrations. All FAME analyses were replicated within the study design (e.g., 5 epilithon samples per sample site). Results for each FAME were reported as relative values ( $\%$ of total FAME).

\section{Data analysis}

Before multivariate analysis, all PUFA (\%) data were arcsine-square-root-transformed for normal distribution approximation and variance stabilization. Multivariate outliers were removed by the minimum volume ellipsoid-based robust distance (Mahalanobis, $R$ package "mvoutlier", Filzmoser \& Gschwandtner, 2018).

Six individual PUFA (LA, ARA, ALA, SDA, EPA, and DHA) were selected for non-metric multidimensional scaling (nMDS) to ordinate the PUFA composition among fish and their food sources (leaves, algae and invertebrates) in two-dimensional space as a function of rank-order dissimilarity (Bray-Curtis). Analysis of similarity (ANOSIM, $R$ package "vegan", 
Oksanen et al., 2019) with 999 permutations was then used to assess similarities in the PUFA composition between food sources (leaves, algae and invertebrates), fish or their organs by ANOSIM global $\mathrm{R}$ value. This value ranges from -1 to +1 . A global $R$ statistic close to 1 indicates that the pair (or a set of samples) is different; an R statistic close to 0 implies that the pair is similar. In greater detail, a global $R$ value of $<0.25$ indicates that groups are hardly separated, $R<0.5$ shows that groups differ but with some overlapping, and $R>0.75$ implies groups are very well separated (Jaschinski et al., 2011). Although not commonly reported, negative values can occur and indicate greater dissimilarity within a group than among groups (Chapman \& Underwood, 1999). In addition, a regression tree (R package "tree", Ripley, 2019) was performed with untransformed proportion data (Online resource 4) to explore patterns between individual PUFA and organisms at different trophic levels and among fish organs or lipid classes. The acceptable level of misclassification was set at $<0.30$. The significance threshold for all data analyses was set at $P<0.05$. For visualization of differences in the PUFA composition between salmonid brain and eye lipid classes, abundant FA other than PUFA: i.e., saturated FA (14:0 = myristic acid, 16:0 = palmitic acid, 18:0 = stearic acid) and monounsaturated FA, oleic acid (18:1n-9) and the diatom biomarker, palmitoleic acid (16:1n-7), were added to the previously selected 6 PUFA to better interpret the position of samples in the ordination space. For all presented ordination plots stress values $<0.1$ were achieved.

\section{Results}

\section{PUFA composition}

The PUFA composition of muscle, liver, brain and eye samples in sedentary (European bullhead) and potentially migratory (Brown and Rainbow trout) fishes differed from that of their potential food sources (macroinvertebrates, epilithon, fresh and conditioned terrestrial leaves) (Fig. 1, Table 1). Basal resources (epilithon, fresh and conditioned leaves) in streams differed significantly from each other in their PUFA composition (ANOSIM; $R=0.84, \quad P<0.001$, $n=84)$. Fresh leaves contained predominantly the short-chain PUFA ALA and LA, whereas conditioned leaves additionally contained traces of SDA and EPA (Table 2). Compared to leaves, epilithon and benthic invertebrates contained high levels of EPA and traces of DHA, which led to a further split in the classification tree between the latter two (online resource 4). Further, epilithon samples contained the highest levels of the diatom biomarker 16:1n-7 (Table 2). Fish differed mostly from their potential resources (macroinvertebrates, epilithon, fresh and conditioned leaves) by their high DHA content, particularly in brain tissue. Nonetheless, the PUFA composition of consumers (benthic macroinvertebrates and fish) was more similar to algal than to terrestrial resources (fresh and conditioned leaves, Table 3).

The organs of both salmonid taxa (S. trutta and $O$. mykiss) did not differ fundamentally in their PUFA composition and will subsequently be referred to as salmonids. The PUFA composition of salmonid organs grouped distinctly from each other (ANOSIM: $R=0.68, P<0.001, n=284$ ), but those of European bullhead overlapped extensively (ANOSIM $R=0.09$, $P=0.002, n=166$ ). However, the FA profiles of the organs still differed from each other in both the salmonids and European bullhead. In both fish taxa, brains had the lowest LA and ALA and the highest DHA content (Table 2). Compared to brains, the eyes contained more LA and ALA, but less EPA than liver and muscle samples, and livers contained the greatest levels of ARA. European bullhead had higher brain ARA and lower liver DHA levels than in salmonids, but muscle PUFA did not differ between the two fish taxa (ANOSIM R $=0.18, P<0.001, n=147$ ). Brain and eye samples of European bullhead (ANOSIM: $R=0.19, P=0.002, n=61$ ) and salmonids (ANOSIM: $R=0.93, P<0.001, n=134)$ were the most dissimilar organs. In both fish taxa, eye PUFA had the highest similarity with dietary PUFA (Table 3) and the highest levels of 16:1n-7 (Table 2).

\section{FA composition in lipid classes of fish brain and eyes}

Salmonid eyes contained 4 times more NL than PL, but their brains had 5 times more PL than NL (online resource 5). The nMDS (Fig. 2) of the FA in the lipid classes of the salmonid brain and eye samples showed that PL differed significantly from NL in both organs (ANOSIM $R=0.89, P<0.001, n=70$, Fig. 2 ). Axis 1 of the nMDS separated brain and eye PL from brain $\mathrm{NL}$ on the basis of their LC-PUFA (correlation 


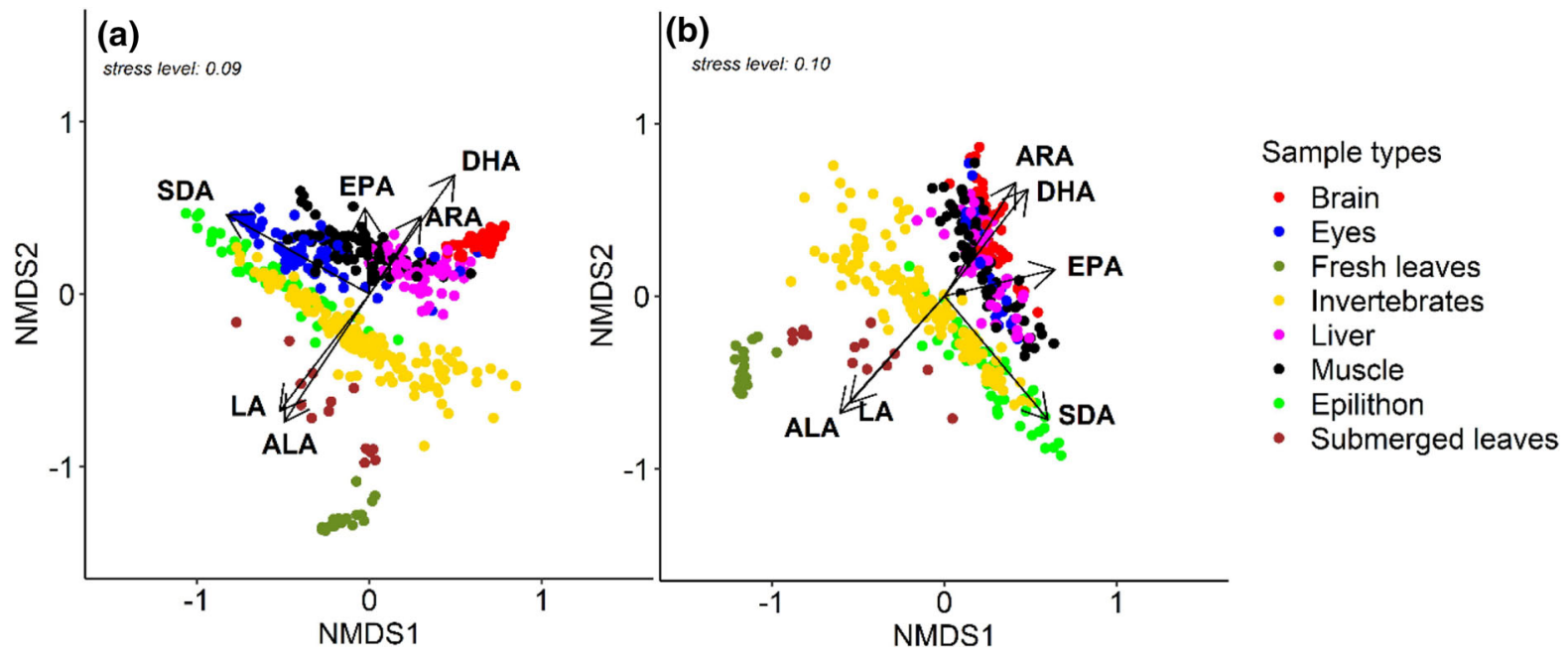

Fig. 1 Non-metric multidimensional scaling (nMDS) of arcsine-square-root-transformed PUFA ( $\%$ of total FAME) of basal resources, benthic invertebrates and a salmonids ( $S$. trutta and $O$. mykiss) and b European Bullhead (C. gobio). ALA alpha- linolenic acid, $S D A$ stearidonic acid, $E P A$ eicosapentaenoic acid, DHA docosahexaenoic acid, $L A$ linoleic acid, ARA arachidonic acid

invertebrates and (a) salmonids (S. trutta and O. mykiss) and (b) European Bullhead (C. gobio)
Table 1 Key statistical parameters of non-metric multidimensional scaling (nMDS) of arcsine-square-root-transformed PUFA ( $\%$ of total FAME) of basal resources, benthic

\begin{tabular}{|c|c|c|c|c|c|}
\hline & \multirow[t]{2}{*}{ FA } & \multicolumn{2}{|c|}{ nMDS scores } & \multirow[t]{2}{*}{$r$} & \multirow[t]{2}{*}{$P$} \\
\hline & & Axis 1 & Axis 2 & & \\
\hline \multirow[t]{6}{*}{ Salmonids } & EPA & -0.05161 & 0.99867 & 0.50 & $<0.001$ \\
\hline & ARA & 0.5554 & 0.83159 & 0.54 & $<0.001$ \\
\hline & DHA & 0.5837 & 0.81197 & 0.85 & $<0.001$ \\
\hline & LA & -0.60997 & -0.79243 & 0.85 & $<0.001$ \\
\hline & ALA & -0.55755 & -0.83014 & 0.89 & $<0.001$ \\
\hline & SDA & -0.87338 & 0.48704 & 0.95 & $<0.001$ \\
\hline \multirow[t]{6}{*}{ European bullhead } & EPA & 0.97165 & 0.23644 & 0.66 & $<0.001$ \\
\hline & ARA & 0.5331 & 0.84605 & 0.78 & $<0.001$ \\
\hline & DHA & 0.61576 & 0.78794 & 0.79 & $<0.001$ \\
\hline & LA & -0.66207 & -0.74944 & 0.83 & $<0.001$ \\
\hline & ALA & -0.66585 & -0.74608 & 0.91 & $<0.001$ \\
\hline & SDA & 0.64262 & -0.76619 & 0.93 & $<0.001$ \\
\hline
\end{tabular}

Vectors (fatty acids, FA) are sorted ascending according to its correlation coefficient $(r)$. ALA alpha-linolenic acid, SDA stearidonic acid, EPA eicosapentaenoic acid, DHA docosahexaenoic acid, $L A$ linoleic acid, $A R A$ arachidonic acid

coefficients: $\quad$ DHA $=0.96, \quad$ ARA $=0.84, \quad$ EPA $=$ $0.48), 18: 1 \mathrm{n}-9(r=0.89)$ and SAFA $(14: 0=0.95$, $18: 0=0.95,16: 0=0.76)$ content. Axis 2 of the nMDS segregated eye NL from brain and eye PL correlated strongly with $\mathrm{C}_{18}$-PUFA $(\mathrm{ALA}=0.92$,
$\mathrm{LA}=0.90, \mathrm{SDA}=0.78)$ and the diatom marker $16: 1 \mathrm{n}-7(r=0.91)$.

Brain- and eye PL were more similar (ANOSIM; $R=0.70, P<0.001, n=38)$ to each other than NL of both these organs (ANOSIM; $R=0.97, P<0.001$, $n=32$ ). Generally, PL in both organs differed from 
Table 2 Individual PUFA (\% of total FAME) among different food-web components in streams (mean \pm 1 standard deviation)

\begin{tabular}{|c|c|c|c|c|c|c|c|c|c|}
\hline Samples & & ALA & SDA & LA & EPA & ARA & DHA & $16: 1 n-7$ & $n$ \\
\hline \multirow[t]{2}{*}{ Terrestrial resources } & Fresh leaves & $37 \pm 20$ & $0 \pm 0$ & $16 \pm 8$ & $0 \pm 0$ & $0 \pm 0$ & $0 \pm 0$ & $1 \pm 0$ & 22 \\
\hline & Conditioned leaves & $31 \pm 4$ & $1 \pm 1$ & $10 \pm 1$ & $1 \pm 1$ & $0 \pm 0$ & $0 \pm 0$ & $1 \pm 1$ & 14 \\
\hline \multirow[t]{2}{*}{ Aquatic resources } & Epilithon & $9 \pm 3$ & $3 \pm 2$ & $7 \pm 2$ & $12 \pm 5$ & $1 \pm 0$ & $1 \pm 0$ & $15 \pm 5$ & 48 \\
\hline & Invertebrates & $10 \pm 4$ & $1 \pm 1$ & $6 \pm 3$ & $14 \pm 6$ & $1 \pm 1$ & $0 \pm 0$ & $8 \pm 4$ & 146 \\
\hline \multirow[t]{4}{*}{ European bullhead } & Brain & $2 \pm 2$ & $1 \pm 0$ & $1 \pm 1$ & $11 \pm 3$ & $4 \pm 1$ & $25 \pm 4$ & $5 \pm 1$ & 37 \\
\hline & Eyes & $6 \pm 4$ & $1 \pm 1$ & $3 \pm 1$ & $8 \pm 2$ & $2 \pm 1$ & $19 \pm 7$ & $7 \pm 3$ & 24 \\
\hline & Liver & $4 \pm 2$ & $1 \pm 1$ & $3 \pm 1$ & $12 \pm 4$ & $5 \pm 2$ & $19 \pm 6$ & $5 \pm 2$ & 48 \\
\hline & Muscle & $5 \pm 3$ & $1 \pm 1$ & $3 \pm 1$ & $18 \pm 4$ & $3 \pm 2$ & $15 \pm 5$ & $5 \pm 3$ & 57 \\
\hline \multirow[t]{4}{*}{ Salmonids } & Brain & $1 \pm 0$ & $0 \pm 0$ & $1 \pm 0$ & $8 \pm 1$ & $1 \pm 0$ & $32 \pm 5$ & $2 \pm 1$ & 70 \\
\hline & Eyes & $10 \pm 4$ & $2 \pm 1$ & $5 \pm 2$ & $7 \pm 2$ & $1 \pm 1$ & $11 \pm 7$ & $12 \pm 4$ & 64 \\
\hline & Liver & $4 \pm 1$ & $1 \pm 0$ & $3 \pm 1$ & $10 \pm 3$ & $4 \pm 2$ & $26 \pm 7$ & $4 \pm 1$ & 60 \\
\hline & Muscle & $7 \pm 3$ & $1 \pm 1$ & $3 \pm 1$ & $13 \pm 3$ & $2 \pm 1$ & $24 \pm 6$ & $5 \pm 2$ & 90 \\
\hline
\end{tabular}

$A L A$ alpha-linolenic acid, SDA stearidonic acid, EPA eicosapentaenoic acid, DHA docosahexaenoic acid, $L A$ linoleic acid, $A R A$ arachidonic acid, $n$ sample size

Table 3 Pairwise similarity (ANOSIM; R) of FA compositions among basal resources, benthic invertebrates and fish (brain, eyes, liver and muscle)

Higher Global $R$ values indicate higher dissimilarity between two or more groups. Asterisks indicate significance levels:

$* * * P \leq 0.001, * * P \leq 0.01$, $* P \leq 0.05$

\begin{tabular}{|c|c|c|c|c|}
\hline \multirow[t]{2}{*}{ Sample types } & \multicolumn{3}{|c|}{ Basal resources } & \multirow[t]{2}{*}{ Invertebrates } \\
\hline & Fresh leaves & Conditioned leaves & Epilithon & \\
\hline \multirow[t]{2}{*}{ Fish (all organs) } & $0.9974 * * *$ & $0.8171 * * *$ & $0.475 * * *$ & $0.4891 * * *$ \\
\hline & $n=472$ & $n=464$ & $n=498$ & $n=596$ \\
\hline \multirow[t]{2}{*}{ Invertebrates } & $0.8899 * * *$ & $0.396 * * *$ & $0.235 * * *$ & - \\
\hline & $n=168$ & $n=160$ & $n=194$ & \\
\hline \multicolumn{5}{|l|}{ European bullhead } \\
\hline \multirow[t]{2}{*}{ Brain } & $1 * * *$ & $0.9932 * * *$ & $0.8148 * * *$ & $0.5109 * * *$ \\
\hline & $n=59$ & $n=51$ & $n=85$ & $n=183$ \\
\hline \multirow[t]{2}{*}{ Eyes } & $1 * * *$ & $0.9278 * * *$ & $0.555 * * *$ & $0.3379 * * *$ \\
\hline & $n=92$ & $n=38$ & $n=72$ & $n=72$ \\
\hline \multirow[t]{2}{*}{ Liver } & $1 * * *$ & $0.9541 * * *$ & $0.617 * * *$ & $0.3214 * * *$ \\
\hline & $n=70$ & $n=62$ & $n=96$ & $n=96$ \\
\hline \multirow[t]{2}{*}{ Muscle } & $1 * * *$ & $0.9103 * * *$ & $0.5438 * * *$ & $0.3195^{* * *}$ \\
\hline & $n=79$ & $n=71$ & $n=105$ & $n=105$ \\
\hline \multicolumn{5}{|l|}{ Salmonids } \\
\hline \multirow[t]{2}{*}{ Brain } & $1 * * *$ & $1 * * *$ & $0.9923 * * *$ & $0.8398 * * *$ \\
\hline & $n=92$ & $n=92$ & $n=118$ & $n=216$ \\
\hline \multirow[t]{2}{*}{ Eyes } & $0.9989 * *$ & $0.8222 * * *$ & $0.1869 * * *$ & $0.3901 * * *$ \\
\hline & $n=86$ & $n=78$ & $n=112$ & $n=210$ \\
\hline \multirow[t]{2}{*}{ Liver } & $1 * * *$ & $0.9973 * * *$ & $0.8943 * * *$ & $0.4348 * * *$ \\
\hline & $n=82$ & $n=74$ & $n=108$ & $n=206$ \\
\hline \multirow[t]{2}{*}{ Muscle } & $1 * * *$ & $0.9607 * * *$ & $0.5857 * * *$ & $0.3974 * * *$ \\
\hline & $n=112$ & $n=104$ & $n=138$ & $n=236$ \\
\hline
\end{tabular}




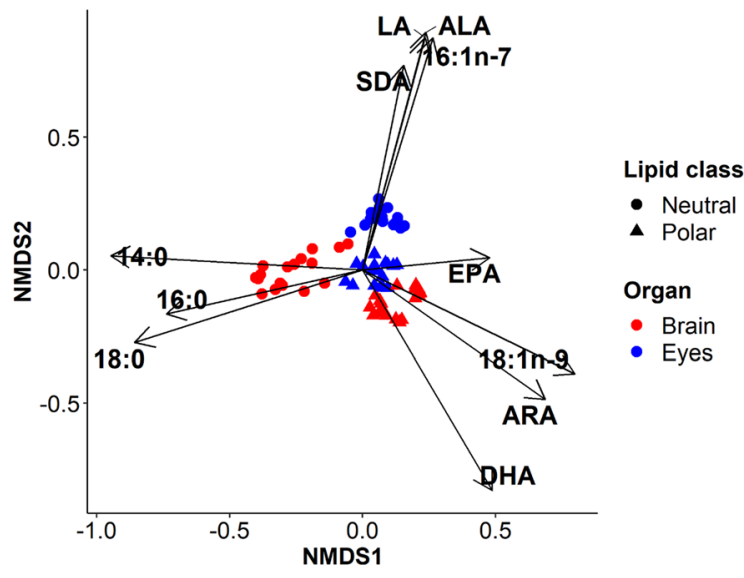

Fig. 2 Non-metric multidimensional scaling (nMDS) of arcsine-square-root-transformed fatty acids ( $\%$ of total FAME) of salmonid (S. trutta and $O$. mykiss) polar and neutral lipids from the brain and eyes. 14:0 = myristic acid, 16:0 = palmitic acid, 18:0 = stearic acid, 18:1n-9 = oleic acid, $A L A$ alpha-linolenic acid, SDA stearidonic acid, EPA eicosapentaenoic acid, DHA docosahexaenoic acid, $L A$ linoleic acid, $A R A$ arachidonic acid

NL by having a higher DHA content (Table 4). Brain PL were characterized by very low levels of LA compared to eyes. Neutral lipids of eyes contained higher contents of ARA than brain NL. Finally, NL of eyes had high contents of ALA, LA, SDA and the diatom biomarker (16:1n-7). Additionally, brain NL were rich in saturated fatty acids (SAFA).

\section{Discussion}

Earlier studies on dietary lipid and transfer along freshwater food webs focused on how dietary energy is passed from sources to whole consumers or selected parts thereof, e.g., dorsal muscle tissue of fish (Ballantyne et al., 2003; Kainz et al., 2004, 2017).
By looking at selected parts of fish only, inferences about dietary energy transfer are limited to these tissues, and cannot be extended to whole organisms, thus limiting comprehensive assessments. This is the first study that shows the dietary transfer of LC-PUFA from epilithon to stream invertebrates and subsequently to various fish tissues, including neural organs.

At the base of stream food webs, we detected a substantial lack of LC-PUFA in terrestrial leaves (submerged and fresh leaves) compared to high EPA contents in epilithon samples. High EPA levels found in biofilms are an important dietary resource supporting somatic growth and reproduction of aquatic invertebrates (Goedkoop et al., 2007; Lau et al., 2008). Conditioned terrestrial leaves contained only traces of EPA, perhaps because of associated microalgae but, similar to earlier studies (Torres-Ruiz et al., 2007; Guo et al., 2016) still provided food of higher nutritional quality than fresh leaves for invertebrates. Naturally occurring terrestrial vascular plants lack the enzymes necessary to synthesize EPA or other LCPUFA and are difficult to digest due to their high lignocellulose content (Brett et al., 2017). Consequently, EPA retention from epilithic biofilms is more beneficial instead of energy-demanding internal bioconversion from precursors. Stream invertebrates have a limited innate ability to transform ALA to EPA ('trophic upgrading') and thus their PUFA composition mostly resembles dietary PUFA (Torres-Ruiz et al., 2007; Masclaux et al., 2012). The PUFA profiles of benthic invertebrates were more similar to epilithon rather than to leaves, confirming that invertebrates mainly depend on algae (Lau et al., 2009; Guo et al., 2017, 2018). As a result, benthic biofilms colonizing stream rocks with a high content of physiologically required EPA convey nutrients of

Table 4 Fatty acid content (\% of total FAME) in brain and eye lipid classes of S. trutta and $O$. mykiss combined (mean \pm 1 standard deviation)

\begin{tabular}{|c|c|c|c|c|c|c|c|c|c|c|c|c|}
\hline Organ & Lipid class & $14: 0$ & $16: 0$ & 18:0 & $18: 1 n-9$ & $16: 1 n-7$ & ALA & SDA & LA & ARA & EPA & DHA \\
\hline \multirow[t]{2}{*}{ Brain } & Neutral & $22 \pm 6$ & $29 \pm 5$ & $24 \pm 7$ & $5 \pm 3$ & $2 \pm 2$ & $1 \pm 2$ & $0 \pm 1$ & $1 \pm 1$ & $0 \pm 0$ & $1 \pm 2$ & $3 \pm 3$ \\
\hline & Polar & $3 \pm 2$ & $20 \pm 2$ & $9 \pm 2$ & $18 \pm 3$ & $2 \pm 1$ & $1 \pm 0$ & $0 \pm 0$ & $0 \pm 0$ & $1 \pm 0$ & $3 \pm 4$ & $23 \pm 4$ \\
\hline \multirow[t]{2}{*}{ Eyes } & Neutral & $5 \pm 3$ & $19 \pm 2$ & $6 \pm 3$ & $12 \pm 3$ & $12 \pm 2$ & $10 \pm 3$ & $3 \pm 2$ & $5 \pm 1$ & $1 \pm 0$ & $2 \pm 4$ & $3 \pm 0$ \\
\hline & Polar & $6 \pm 4$ & $23 \pm 4$ & $13 \pm 4$ & $12 \pm 3$ & $6 \pm 2$ & $3 \pm 1$ & $1 \pm 0$ & $2 \pm 1$ & $1 \pm 0$ & $2 \pm 4$ & $15 \pm 4$ \\
\hline
\end{tabular}

14:0 = myristic acid, 16:0 = palmitic acid, 18:0 = stearic acid, 18:1n-9 = oleic acid, $A L A$ alpha-linolenic acid, $S D A$ stearidonic acid, $E P A$ eicosapentaenoic acid, DHA docosahexaenoic acid, $L A$ linoleic acid, ARA arachidonic acid 
higher dietary high-quality conducive for consumer growth, than does terrestrial vegetation.

There was an evident mismatch between dietary LC-PUFA (terrestrial leaves, epilithon and aquatic invertebrates) and riverine fish, as previously noted by Guo et al. (2017). Fish need long-chain PUFA for optimal somatic growth and reproduction (Bell \& Sargent, 2003; Ahlgren et al., 2009). Several feeding experiments have shown negative effects of LC-PUFA deficient diets on the growth rates of fish (Murray et al., 2014) or metabolic rates in birds (Twining et al., 2016) that may be related to the metabolic costs associated with converting dietary precursor PUFA (e.g., ALA or LA) to LC-PUFA. In late fall, the input of terrestrial insects to streams plays only a minor role in salmonid diets (Nakano \& Murakami, 2001). Consequently, in this study only benthic invertebrates offered an optimal source of algal n-3 PUFA, in particular EPA (Ghioni et al., 1996), for further conversion, at levels that are sufficient for proper functioning in freshwater fish, even though past experimental studies have claimed low conversion rates (Buzzi et al., 1996). Previous research indicated a substantial contribution of algal carbon to consumer biomass is by stable isotope data, ranging from small tropical headwater streams (Lau et al., 2009) to large arid rivers (Bunn et al., 2013). Furthermore, isotopic evidence suggests most of the nitrogen assimilated by stream consumers is of algal origin, even in systems where there appears to be a significant terrestrial carbon contribution (Brett et al., 2017; Thorp \& Bowes, 2017).

The high PUFA similarity between liver and muscle suggests that livers retained or endogenously transformed dietary PUFA and allocated them to muscles (Martin et al., 1994). Higher DHA levels in salmonid than in European bullhead livers could be the result of higher conversion rates or greater incorporation of dietary DHA from prey fish. However, given the fact that salmonids in this study were small and piscivory is not the primary mode of feeding for this size class (Elliott, 1973; Behnke et al., 2002), the high similarity between liver PUFA of European bullhead and both salmonid taxa (S. trutta and O. mykiss) implies that both were equally able to retain ALA and LA and further minimize potential dietary deficiencies in long-chain PUFA by endogenous conversion.

The ANOSIM results indicate that the PUFA composition in organs of both salmonid taxa (S. trutta and $O$. mykiss) were more similar to each other than to European bullhead. Gladyshev et al. (2018) reported that phylogeny (order identity) outweighs food or habitat as factors in fish muscle FA. In line with this argument, we argue that species identity could explain the high PUFA similarities between all sampled organs of Rainbow and Brown trout. Despite similar brain DHA content among both fish groups, the brain, and eyes of European bullhead contained more ARA than salmonids. This is also indicated by the more similar vector scores of DHA and ARA in the ordination plots of European bullhead than salmonids. Both ARA and EPA are associated with eicosanoid synthesis (e.g., prostaglandins) and act as hormone precursors (Sargent et al., 1995). Increased ARA content in brains and eyes of European bullhead could be related to spawning activities (Stacey \& Goetz, 1982) as suggested by the presence of egg-bearing females observed during our sampling. Higher reproductive activities in European bullhead compared to salmonids are likely to have resulted in higher PUFA allocation and could explain higher similarities among organ PUFA. Changes in the FA composition due to reproductive activities were reported for gonadal, muscle, and liver tissues (Nogueira et al., 2017; Keva et al., 2019), but impacts on neural tissues have not been assessed yet. Other factors related to foraging behavior, eye anatomy or visual capabilities (Elliott, 1973; Mills \& Mann, 1983; Guthrie, 1986; Wagner, 1990) could lead to differences in PUFA composition in brain and eye between European bullhead and salmonids, but further studies investigating such functional differences are still warranted.

The high dissimilarity in PUFA of salmonid brain and eyes was unexpected, but largely accounted for by differences in the lipid classes between these neural organs with direct implications for their PUFA composition: higher resemblance of dietary FA in eyes than brains (Bell \& Dick, 1991; Tocher, 1993; Buzzi et al., 1996). This is consistent with other studies which showed that dietary inputs can significantly affect eye lipids (Bell et al., 1995; Brodtkorb et al., 1997; Navarro et al., 1997). Eyes store dietary FA for reasons that are still not fully understood. For example, apart from being major energy store, NL in eyes may serve as reservoir for membrane FA synthesis (Linares \& Henderson, 1991). Similar to Brodtkorb et al. (1997), brain NL were composed predominantly of SAFA and when required, these 
could serve as energy source (De Roos, 1994) even if most energy is mobilized from glycogen in teleost brains (Soengas \& Aldegunde, 2002). The high abundance of the monosaturated FA 18:1n-9 was reported in total lipids (Tocher \& Harvie, 1988; Stoknes et al., 2004; Amlund et al., 2012) and the membrane lipids (Brodtkorb et al., 1997) of neural tissues (brain and eyes) of trout, salmon and marine fish species (Geurden et al., 1998). Farkas et al. (2000) suggested that high levels of 18:1n-9 and 22:6n-3 in fish membranes are required for proper fusion and signal transduction rates in cold-adapted animals. Although entire eyeballs were analyzed, the high similarity between PL of eyes and brain imply the provision of LC-PUFA to the retina may suffice even if basal diet sources in stream food webs are deficient in n-3 LC-PUFA. Such dietary shortage of n-3 LCPUFA is, to varying degrees, compensated in stream fish via dietary PUFA conversion to target PUFA, such as DHA, that are required for neural organs. Consequently, the low dietary availability of DHA in the trophic base of these subalpine streams might not have impaired the visual acuity or proper functioning of sensory systems of fish.

Our large-scale field study provides further evidence that algal PUFA support fish in headwater stream habitats. Contrary to the implications of the River Continuum Concept, algae rather than terrestrial sources supplied aquatic vertebrates with high-quality biomolecules (e.g., PUFA) required for neurogenesis. Algal PUFA that were first incorporated by benthic invertebrates serve subsequently as precursors for critical PUFA required for fish organs, in particular for DHA in fish brains and eyes. Based on these data, it is not possible to differentiate whether DHA was allocated from livers to respective organs or if DHA production occurred locally, e.g., in brain astrocytes (Mourente et al., 1991; Bell et al., 2001; Tocher et al., 2006). Future efforts to elucidate trophic and allocation pathways of individual n-3 PUFA in fish organs and dietary sources require compound-specific stable isotope analyses of individual FA (Kühmayer et al., 2020).

Acknowledgements This study was supported by the Austrian Science Fund (FWF Project P28903-B25) and the NÖ Forschungs- und Bildungsges.m.b.H. (NFB) through the Life Science Call 2016 (Project ID: SC16-035). We thank Hannes Hager, Katharina Winter, Stefanie Danner and Miriam Jehle for assistance in the field and lab, Ulrich Zangerl from the
Department of Geography and Regional Research (University of Vienna) for GIS support, and comments of two anonymous reviewers that helped us improve this manuscript.

Funding Open access funding provided by Austrian Science Fund (FWF).

Open Access This article is licensed under a Creative Commons Attribution 4.0 International License, which permits use, sharing, adaptation, distribution and reproduction in any medium or format, as long as you give appropriate credit to the original author(s) and the source, provide a link to the Creative Commons licence, and indicate if changes were made. The images or other third party material in this article are included in the article's Creative Commons licence, unless indicated otherwise in a credit line to the material. If material is not included in the article's Creative Commons licence and your intended use is not permitted by statutory regulation or exceeds the permitted use, you will need to obtain permission directly from the copyright holder. To view a copy of this licence, visit http://creativecommons.org/licenses/by/4.0/.

\section{References}

Agaba, M. K., D. R. Tocher, X. Zheng, C. A. Dickson, J. R. Dick \& A. J. Teale, 2005. Cloning and functional characterisation of polyunsaturated fatty acid elongases of marine and freshwater teleost fish. Comparative Biochemistry and Physiology, Part B 142: 342-352.

Ahlgren, G., P. Blomqvist, M. Boberg \& I.-B. Gustafsson, 1994. Fatty acid content of the dorsal muscle - an indicator of fat quality in freshwater fish. Journal of Fish Biology 45: 131-157.

Ahlgren, G., T. Vrede \& W. Goedkoop, 2009. Fatty acid ratios in freshwater fish, zooplankton and zoobenthos-are there specific optima? In Arts, M. T., M. T. Brett \& M. J. Kainz (eds), Lipids in Aquatic Ecosystems. Springer, New York: 147-178.

Amlund, H., L. Andreasen \& B. E. Torstensen, 2012. Dietary methylmercury and vegetable oil affects brain lipid composition in Atlantic salmon (Salmo salar L.). Food and Chemical Toxicology Elsevier Ltd 50: 518-525.

Arts, M. T., M. T. Brett \& M. J. Kainz, 2009. Lipids in aquatic ecosystems. Springer, New York.

Ballantyne, A. P., M. T. Brett \& D. E. Schindler, 2003. The importance of dietary phosphorus and highly unsaturated fatty acids for sockeye (Oncorhynchus nerka) growth in Lake Washington-a bioenergetics approach. Canadian Journal of Fisheries and Aquatic Sciences 60: 12-22.

Bazan, N. G., 2005. Neuroprotectin D1 (NPD1): a DHAderived mediator that protects brain and retina against cell injury-induced oxidative stress. Brain Pathology (Zurich, Switzerland) 15: 159-166.

Behnke, R. J., J. Tomelleri \& D. S. Proebstel, 2002. Trout and Salmon of North America. Free Press, New York. 
Bell, M. V. \& J. R. Dick, 1991. Molecular species composition of the major diacyl glycerophospholipids from muscle, liver, retina and brain of Cod (Gadus morhua). Lipids 26: $565-573$.

Bell, J. G. \& J. R. Sargent, 2003. Arachidonic acid in aquaculture feeds: current status and future opportunities. Aquaculture 218: 491-499.

Bell, M. V., R. S. Batty, J. R. Dick \& K. Fretwell, 1995. Dietary deficiency of docosahexaenoic acid impairs vision at low light intensities in juvenile Herring (Clupea harengus L.). Lipids 30: 901-905.

Bell, M. V., J. R. Dick \& A. E. A. Porter, 2001. Biosynthesis and tissue deposition of docosahexaenoic acid (22:6n-3) in Rainbow Trout (Oncorhynchus mykiss). Lipids 36: 1153-1159.

Besemer, K., G. Singer, C. Quince, E. Bertuzzo, W. Sloan \& T. J. Battin, 2013. Headwaters are critical reservoirs of microbial diversity for fluvial networks. Proceedings of the Royal Society B: Biological Sciences 280: 20131760.

Brett, M. \& D. Müller-Navarra, 1997. The role of highly unsaturated fatty acids in aquatic foodweb processes. Freshwater Biology 38: 483-499.

Brett, M. T., M. J. Kainz, S. J. Taipale \& H. Seshan, 2009. Phytoplankton, not allochthonous carbon, sustains herbivorous zooplankton production. Proceedings of the National Academy of Sciences 106: 21197-21201.

Brett, M. T., S. E. Bunn, S. Chandra, A. W. E. Galloway, F. Guo, M. J. Kainz, P. Kankaala, D. C. P. Lau, J. H. Thorp, J. D. Wehr, T. P. Moulton, M. E. Power, J. B. Rasmussen \& S. J. Taipale, 2017. How important are terrestrial organic carbon inputs for secondary production in freshwater ecosystems? Freshwater Biology 62: 833-853.

Brodtkorb, T., G. Rosenlund \& O. Lie, 1997. Effects of dietary levels of 20:5n-3 and 22:6n-3 on tissue lipid composition in juvenile atlantic salmon, Salmo salar, with emphasis on brain and eye. Aquaculture Nutrition 3: 175-187.

Budge, S. M., S. J. Iverson \& H. N. Koopman, 2006. Studying trophic ecology in marine ecosystems using fatty acids: a primer on analysis and interpretation. Marine Mammal Science 22: 759-801.

Bunn, S. E., C. Leigh \& T. D. Jardine, 2013. Diet-tissue fractionation of $\delta^{15} \mathrm{~N}$ by consumers from streams and rivers. Limnology and Oceanography 58: 765-773.

Buzzi, M., R. J. Henderson \& J. R. Sargent, 1996. The desaturation and elongation of linolenic acid and eicosapentaenoic acid by hepatocytes and liver microsomes from rainbow trout (Oncorhynchus mykiss) fed diets containing fish oil or olive oil. Biochimica et Biophysica ActaLipids and Lipid Metabolism 1299: 235-244.

Chapman, M. G. \& A. J. Underwood, 1999. Ecological patterns in multivariate assemblages: information and interpretation of negative values in ANOSIM tests. Marine Ecology Progress Series 180: 257-265.

De Roos, R., 1994. Plasma ketone, glucose, lactate, and alanine levels in the vascular supply to and from the brain of the spiny dogfish shark (Squalus acanthias). Journal of Experimental Zoology 268: 354-363.

Elliott, J. M., 1973. The food of brown and rainbow trout (Salmo trutta and S. gairdneri) in relation to the abundance of drifting invertebrates in a mountain stream. Oecologia 12: 329-347.
Farkas, T., K. Kitajka, E. Fodor, I. Csengeri, E. Lahdes, Y. K. Yeo, Z. Krasznai \& J. E. Halver, 2000. Docosahexaenoic acid-containing phospholipid molecular species in brains of vertebrates. Proceedings of the National Academy of Sciences 97: 6362-6366.

Filzmoser, P., \& M. Gschwandtner, 2018. R-Package: 'mvoutlier' - Multivariate Outlier Detection Based on Robust Methods.

Geurden, I., O. Reyes, P. Bergot, P. Coutteau \& P. Sorgeloos, 1998. Incorporation of fatty acids from dietary neutral lipid in eye, brain and muscle of postlarval turbot fed diets with different types of phosphatidylcholine. Fish Physiology and Biochemistry 19: 365-375.

Ghioni, C., J. G. Bell \& J. R. Sargent, 1996. Polyunsaturated fatty acids in neutral lipids and phspholipids of some freshwater insects. Comparative Biochemistry and Physiology 114: 161-170.

Gladyshev, M. I., N. N. Sushchick, A. P. Tolomeev \& Y. Y. Dgebuadze, 2018. Meta-analysis of factors associated with omega-3 fatty acid contents of wild fish. Reviews in Fish Biology and Fisheries Springer International Publishing 28: 277-299.

Goedkoop, W., M. Demandt \& G. Ahlgren, 2007. Interactions between food quantity and quality (long-chain polyunsaturated fatty acid concentrations) effects on growth and development of Chironomus riparius. Canadian Journal of Fisheries and Aquatic Sciences 64: 425-436.

Guo, F., M. J. Kainz, F. Sheldon \& S. E. Bunn, 2015. Spatial variation in periphyton fatty acid composition in subtropical streams. Freshwater Biology 60: 1411-1422.

Guo, F., M. J. Kainz, D. Valdez, F. Sheldon \& S. E. Bunn, 2016. High-quality algae attached to leaf litter boost invertebrate shredder growth. Freshwater Science 35: 1213-1221.

Guo, F., S. E. Bunn, M. T. Brett \& M. J. Kainz, 2017. Polyunsaturated fatty acids in stream food webs-high dissimilarity among producers and consumers. Freshwater Biology 62: 1325-1334.

Guo, F., S. E. Bunn, M. T. Brett, B. Fry, H. Hager, X. Ouyang \& M. J. Kainz, 2018. Feeding strategies for the acquisition of high-quality food sources in stream macroinvertebrates: collecting, integrating, and mixed feeding. Limnology and Oceanography 63: 1964-1978.

Guthrie, D. M., 1986. Role of vision in fish behaviour. In Pitcher, T. J. (ed.), Behaviour of Teleost Fishes. Springer, Boston, MA: 89-128.

Hixson, S. M., B. Sharma, M. J. Kainz, A. Wacker \& M. T. Arts, 2015. Production, distribution, and abundance of longchain omega-3 polyunsaturated fatty acids: a fundamental dichotomy between freshwater and terrestrial ecosystems. Environmental Reviews 424: 414-424.

Hong, H., Y. Zhou, H. Wu, Y. Luo \& H. Shen, 2014. Lipid content and fatty acid profile of muscle, brain and eyes of seven freshwater fish: a comparative study. Journal of the American Oil Chemists' Society 91: 795-804.

Ishizaki, Y., R. Masuda, K. Uematsu, K. Shimizu, M. Arimoto \& T. Takeuchi, 2001. The effect of dietary docosahexaenoic acid on schooling behaviour and brain development in larval yellowtail. Journal of Fish Biology 58: 1691-1703.

Iverson, S. J., 2009. Tracing aquatic food webs using fatty acids: from qualitative indicators to quantitative determination. 
In Arts, M. T., M. T. Brett \& M. J. Kainz (eds), Lipids in Aquatic Ecosystems. Springer, New York: 281-307.

Jaschinski, S., D. C. Brepohl \& U. Sommer, 2011. Seasonal variation in carbon sources of mesograzers and small predators in an eelgrass community: stable isotope and fatty acid analyses. Marine Ecology Progress Series 431: 69-82.

Kainz, M., M. T. Arts \& A. Mazumder, 2004. Essential fatty acids in the planktonic food web and their ecological role for higher trophic levels. Limnology and Oceanography 49: 1784-1793.

Kainz, M. J., H. Hager, S. Rasconi, K. K. Kahilainen, P.-A. Amundsen \& B. Hayden, 2017. Polyunsaturated fatty acids in fishes increase with total lipids irrespective of feeding sources and trophic position. Ecosphere 8: 13.

Keva, O., R. Käkelä, P. Tang, B. Hayden, S. Taipale, C. Harrod \& K. K. Kahilainen, 2019. Seasonal changes in European whitefish muscle and invertebrate prey fatty acid composition in a subarctic lake. Freshwater Biology 64: 1908-1920.

Kühmayer, T., F. Guo, N. Ebm, T. J. Battin, M. T. Brett, S. E. Bunn, B. Fry \& M. J. Kainz, 2020. Preferential retention of algal carbon in benthic invertebrates - stable isotopes and fatty acids evidence from an outdoor flume experiment. Freshwater Biology 65: 1200-1209.

Lau, D. C. P., K. M. Y. Leung \& D. Dudgeon, 2008. Experimental dietary manipulations for determining the relative importance of allochthonous and autochthonous food resources in tropical streams. Freshwater Biology 53: 139-147.

Lau, D. C. P., K. M. Y. Leung \& D. Dudgeon, 2009. Are autochthonous foods more important than allochthonous resources to benthic consumers in tropical headwater streams? Journal of the North American Benthological Society 28: 426-439.

Linares, F. \& R. J. Henderson, 1991. Incorporation of 14Clabelled polyunsaturated fatty acids by juvenile turbot, Scophthalmus maximus (L.) in vivo. Journal of Fish Biology 38: 335-347.

Lund, I., E. Höglund, L. O. E. Ebbesson \& P. V. Skov, 2014. Dietary LC-PUFA deficiency early in ontogeny induces behavioural changes in pike perch (Sander lucioperca) larvae and fry. Aquaculture 432: 453-461.

Martin, R. E., E. B. Rodriguez de Turco \& N. G. Bazan, 1994. Developmental maturation of hepatic n-3 polyunsaturated fatty acid metabolism: supply of docosahexaenoic acid to retina and brain. The Journal of Nutritional Biochemistry 5: 151-160.

Masclaux, H., A. Bec, M. J. Kainz, F. Perrière, C. Desvilettes \& G. Bourdier, 2012. Accumulation of polyunsaturated fatty acids by cladocerans: effects of taxonomy, temperature and food. Freshwater Biology 57: 696-703.

Mills, C. A. \& R. H. K. Mann, 1983. The Bullhead Cottus gobio, a versatile and successful fish. Annnual Report of the Freshwater Biological Association 51: 76-88.

Mohd-Yusof, N. Y., O. Monroig, A. Mohd-Adnan, K.-I. Wan \& D. R. Tocher, 2010. Investigation of highly unsaturated fatty acid metabolism in the Asian sea bass, Lates calcarifer. Fish Physiology and Biochemestry 36: 827-843.

Mourente, G. \& D. Tocher, 1998. The in vivo incorporation and metabolism of $\left[1-{ }^{14} \mathrm{C}\right]$ linolenate $(18: 3 \mathrm{n}-3)$ in liver, brain and eyes of juveniles of rainbow trout Oncorhynchus mykiss L and gilthead sea bream Sparus aurata L. Fish Physiology and Biochemistry 18: 149-165.

Mourente, G., D. R. Tocher \& J. R. Sargent, 1991. Specific accumulation of docosahexaenoic acid (22: $6 n-3)$ in brain lipids during development of juvenile turbot Scophthalmus maximus L. Lipids 26: 871-877.

Müller-Navarra, D. C., M. T. Brett, A. M. Liston \& C. R. Goldman, 2000. A highly unsaturated fatty acid predicts carbon transfer between primary producers and consumers. Nature 403: 74-77.

Murray, D. S., H. Hager, D. R. Tocher \& M. J. Kainz, 2014. Effect of partial replacement of dietary fish meal and oil by pumpkin kernel cake and rapeseed oil on fatty acid composition and metabolism in Arctic charr (Salvelinus alpinus). Aquaculture 431: 85-91.

Nakano, S. \& M. Murakami, 2001. Reciprocal subsidies: dynamic interdependence between terrestrial and aquatic food webs. Proceedings of the National Academy of Sciences of the United States of America 98: 166-170.

Napier, J. A., 2006. The production of n-3 long-chain polyunsaturated fatty acids in transgenic plants. European Journal of Lipid Science and Technology 108: 965-972.

Navarro, J. C., L. A. McEvoy, M. V. Bell, F. Amat, F. Hontoria \& J. R. Sargent, 1997. Effect of different dietary levels of

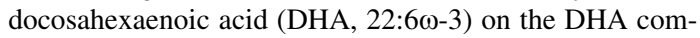
position of lipid classes in sea bass larvae eyes. Aquaculture International 5: 509-516.

Nogueira, N., I. Fernandes, T. Fernandes \& N. Cordeiro, 2017. A comparative analysis of lipid content and fatty acid composition in muscle, liver and gonads of Seriola fasciata Bloch 1793 based on gender and maturation stage. Journal of Food Composition and Analysis 59: 68-73.

Oksanen, J., F. G. Blanchet, M. Friendly, R. Kindt, P. Legendre, D. Mcglinn, P. R. Minchin, R., B. Hara, G. L. Simpson, P. Solymos, M. H. H. Stevens, \& E. Szoecs, 2019. R Package "vegan". https://github.com/vegandevs/vegan.

Ripley, B., 2019. R-Package "tree”. https://CRAN.R-project. org/package $=$ tree.

Sargent, J. R., J. G. Bell, M. V. Bell, R. J. Henderson \& D. R. Tocher, 1995. Requirement criteria for essential fatty acids. Journal of Applied Ichthyology 11: 183-198.

Soengas, J. L. \& M. Aldegunde, 2002. Energy metabolism of fish brain. Comparative Biochemistry and PhysiologyPart B Biochemistry and Molecular Biology 131(3): 271-296.

Stacey, N. E. \& F. W. Goetz, 1982. Role of prostaglandins in fish reproduction. Canadian Journal of Fisheries and Aquatic Sciences 39: 92-98.

Stoknes, I. S., H. M. W. Økland, E. Falch \& M. Synnes, 2004. Fatty acid and lipid class composition in eyes and brain from teleosts and elasmobranchs. Comparative Biochemistry and Physiology—Part B Biochemistry and Molecular Biology 138: 183-191.

Sushchik, N. N., I. V. Zuev, G. S. Kalachova, A. V. Ageev \& M. I. Gladyshev, 2018. Content of highly unsaturated fatty acids in fish from rivers of contrasting temperature. River Research and Applications 34: 565-574.

Sushchik, N. N., O. N. Makhutova, A. E. Rudchenko, L. A. Glushchenko, S. P. Shulepina, A. A. Kolmakova \& M. I. Gladyshev, 2020. Comparison of fatty acid contents in 
major lipid classes of seven salmonid species from Siberian Arctic Lakes. Biomolecules 10: 1-20.

Thorp, J. H. \& R. E. Bowes, 2017. Carbon sources in riverine food webs: new evidence from amino acid isotope techniques. Ecosystems 20: 1029-1041.

Tocher, D. R., 1993. Elongation predominates over desaturation in the metabolism of $18: 3 n-3$ and $20: 5 n-3$ in Turbot (Scophthalmus maximus) brain astroglial cells in primary culture. Lipids 28: 267-272.

Tocher, D. R. \& D. G. Harvie, 1988. Fatty acid compositions of the major phosphoglycerides from fish neural tissues; (n-3) and (n-6) polyunsaturated fatty acids in rainbow trout (Salmo gairdneri) and cod (Gadus morhua) brains and retinas. Fish Physiology and Biochemistry 5: 229-239.

Tocher, D. R., J. G. Bell, P. MacGlaughlin, F. McGhee \& J. R. Dick, 2001. Hepatocyte fatty acid desaturation and polyunsaturated fatty acid composition of liver in salmonids: effects of dietary vegetable oil. Comparative Biochemistry and Physiology-B Biochemistry and Molecular Biology 130: 257-270.

Tocher, D. R., X. Zheng, C. Schlechtriem, N. Hastings, J. R. Dick \& A. J. Teale, 2006. Highly unsaturated fatty acid synthesis in marine fish: cloning, functional characterization, and nutritional regulation of fatty acyl $\Delta 6$ desaturase of atlantic cod (Gadus morhua L.). Lipids 41: 1003-1016.

Torres-Ruiz, M., J. D. Wehr \& A. A. Perrone, 2007. Trophic relations in a stream food web: importance of fatty acids for macroinvertebrate consumers. Journal of the North American Benthological Society University of Chicago Press 26: 509-522.

Torres-Ruiz, M., J. D. Wehr \& A. A. Perrone, 2010. Are netspinning caddisflies what they eat? An investigation using controlled diets and fatty acids. Journal of the North American Benthological Society 29: 803-813.

Twining, C. W., J. T. Brenna, P. Lawrence, J. R. Shipley, T. N. Tollefson \& D. W. Winkler, 2016. Omega-3 long-chain polyunsaturated fatty acids support aerial insectivore performance more than food quantity. Proceedings of the National Academy of Sciences of the United States of America 113: 10920-10925.

Volk, C. \& P. Kiffney, 2012. Comparison of fatty acids and elemental nutrients in periphyton, invertebrates, and cutthroat trout (Oncorhynchus clarki) in conifer and alder streams of western Washington state. Aquatic Ecology 46: 85-99.

Wagner, H. J., 1990. Retinal structure of fishes. In Douglas, R. \& M. Djamgoz (eds), The Visual System of Fish. Springer, Dordrecht: 109-157.

Publisher's Note Springer Nature remains neutral with regard to jurisdictional claims in published maps and institutional affiliations. 